\title{
Transcatheter closure for patent ductus arteriosus in patients with Eisenmenger syndrome: to do or not?
}

\author{
Jing $\mathrm{Xu}^{\dagger}$, Liang Wang ${ }^{\dagger}$, Yunli Shen, Liang Geng and Fadong Chen ${ }^{*}$ (i)
}

\begin{abstract}
Background: Patent ductus arteriosus (PDA) complicated by Eisenmenger syndrome (ES) remains to be a major cause of morbidity and mortality worldwide. Giving increasing evidences of benefit from targeted therapies, ES patients once thought to be inoperable may have increasing options for management. This study aims to explore whether PDA in patients with ES can be treated with transcatheter closure (TCC).
\end{abstract}

Methods: Between August 2014 and July 2016, four of fifteen PDA-ES patients whose Qp/Qs improved significantly and Qp/Qs > 1.5 after acute vasodilator testing with 100\% oxygen were selected to receive TCC and pulmonary vasodilator therapy. PAH-targeted drugs were prescribed before and after occlusion for all. Trial occlusion was performed before permanent closure.

Results: The first TCC failed after initiation of PAH-targeted drugs for 6 months in four patients. After the medication was adjusted and extended to 12 months, TCC was performed for all without hemodynamic intolerances during perioperative period. Pulmonary artery systolic pressure (PASP) was significantly decreased ( $\geq 40 \%)$ immediately after TCC. During a mean follow-up of $48 \pm 14.70$ months, there were a further decrease of PASPs in two patients, the other two showed improved pulmonary vascular resistance, WHO functional class and six-minute walking distance despite deteriorated PASP.

Conclusion: Some selected PDA-ES patients might benefit from TCC and combined PAH-targeted drugs play a crucial role.

Keywords: Patent ductus arteriosus, Eisenmenger syndrome, Transcatheter closure, Diagnostic treatment and repair strategy, Targeted drugs

\section{Background}

Patent ductus arteriosus (PDA) is one of the most common congenital heart defects (CHDs). Without timely correction, vasomotor dysfunction of endothelial cells and vascular remodeling will develop gradually in pulmonary arteries, leading to increased pulmonary vascular

\footnotetext{
*Correspondence: chenfadong0819@163.com

${ }^{\dagger}$ Jing Xu and Liang Wang contribute equally to this article

Department of Cardiology, Shanghai East Hospital, Shanghai Tongji

University School of Medicine, No. 150, Jimo Road, Pudong District,

Shanghai 200120, China
}

resistance (PVR), severe pulmonary arterial hypertension (PAH) and eventually Eisenmenger syndrome (ES) which remains to be a major cause of morbidity and mortality worldwide [1, 2]. Additionally, in developing countries such as China, PDA associated with ES is common because CHDs are not detectable until adulthood and thereby ES has developed. This situation is now becoming a frontier issue.

Transcatheter closure (TCC) for PDA has been established as a safe and effective alternative to surgical closure with the advancement and improvement of techniques 
and materials [3]. However, TCC is generally considered as contraindicated for ES patients due to irreversible obstructive lesions of the pulmonary vasculature in the past clinical practice.

Recently, giving increasing evidence of benefit from targeted therapies [4], ES patients once thought to be inoperable may have increasing options for management $[5,6]$. Patients with severe PAH are amenable to receive surgery or TCC after successful treatment with targeted drugs [7-9]. However, the immediate and long-term prognosis with such patients is unknown.

In this study, we aim to study the change of pulmonary artery systolic pressure (PASP), cardiac function and hemodynamic variables of four PDA-ES patients who underwent TCC and pulmonary vasodilator therapy by diagnostic treatment and repair strategy with long-term follow-up, in order to identify whether PDA-ES patients can benefit from TCC.

\section{Methods \\ Patients}

The records of fifteen patients with clinical and echocardiographic findings of PDA and ES were retrospectively reviewed from August 2014 to July 2016. The inclusion criteria for ES are based on European guidelines [10]. Each patient was evaluated by arterial blood gas analysis, six-minute walking distance (6MWD), World Health Organization functional class (WHO FC), echocardiography and finally right heart catheterization (RHC). This study was conducted in accordance with the amended Declaration of Helsinki. Written informed consents were obtained from all the patients.

\section{Hemodynamic measurement}

RHC was performed with Swan-Ganz catheter (Edwards 774,7.5F) and monitoring system (Edwards Lifesciences LLC, Vigilance II). All measurements were performed in supine position. Hemodynamic parameters included right atrial pressure (RAP), pulmonary artery pressure (PAP) and pulmonary artery wedge pressure (PAWP). Cardiac output (CO) were assessed using the Fick's method before TCC or continuous thermodilution method during follow-up. Arterial blood gases and mixed venous oxygen generation $\left(\mathrm{SvO}_{2}\right)$ were also measured. Pulmonary to systemic flow ratio (Qp/Qs), PVR and systemic vascular resistance (SVR) were calculated using standard formulas. All measurements were made in a stable baseline condition without oxygen for $2 \mathrm{~h}$ at least.

Acute vasodilator testing was then performed with oxygen. Standardized oxygen was provided via standard commercial equipment at a flow rate of $8 \mathrm{~L} / \mathrm{min}$, achieving an oxygen saturation of $100 \%$ in every patient.
Oxygen was applied at least $10 \mathrm{~min}$. Hemodynamic parameters, particularly Qp/Qs, were again recorded. Qp/Qs > 1.5 after inhalation of $100 \%$ oxygen was defined as an absolute cutoff value to screen the candidates for our study.

\section{Intervention procedure}

Under local anesthesia and transthoracic echocardiographic guidance, interventional procedure was performed after percutaneous puncture of the femoral artery and vein. Morphology of PDA was demonstrated by descending aorta angiography with $6 \mathrm{~F}$ pigtail catheter, and the narrowest diameter of PDA was measured meanwhile. Trial occlusion using PDA occluder(Shanghai Shape Memory Alloy Ltd, China) was performed for $30 \mathrm{~min}$ to measure the change of hemodynamic data. The occluder was released when all the following criteria were satisfied after trial occlusion: (1) a decrease in PASP $\geq 40 \%$; (2) no decrease in aortic pressure (AOP); (3) an increase in systemic arterial oxygen saturation $\left(\mathrm{SaO}_{2}\right)$.

\section{Follow-up}

The patients were followed up in out-patient clinic every 6 months after discharge with the last follow-up in August 2020. 6MWD, transthoracic echocardiography and blood gas analysis were routinely carried out. The hemodynamic evaluations by RHC were assessed in case 2,3,4 at 72,48,36 months follow-up, respectively.

\section{Results}

\section{Study patients}

After diagnosis by initial RHC and acute vasodilator testing, four ( 3 female and 1 male) of fifteen PDA-ES patients were finally selected to be treated with $\mathrm{PAH}$-targeted drugs and subsequent TCC (Fig. 1).

The mean age of the four PDA-ES patients were 28.5 years (ranging from 19 to 34 years) with WHO FCIIIII. Baseline demographic characteristics and echocardiography parameters were shown in Table 1.

The mean PVR was 22.19 Wood U (ranging from 14.70 to 36.91 Wood U). The mean PASP and AOP were $126 \mathrm{mmHg}$ (ranging from 105 to $145 \mathrm{mmHg}$ ) and $129 \mathrm{mmHg}$ (ranging from 113 to $144 \mathrm{mmHg}$ ), respectively. Baseline hemodynamic parameters obtained by RHC and the changes of Qp/Qs after 100\% oxygen inhalation were shown in Table 2.

\section{Diagnostic treatment and repair strategy}

After initiation of PAH-targeted therapy for 6 months, the first TCC attempt failed because PASPs of the four patients during trial occlusion did not decrease or the reduction was less than 20\%. After targeted therapy was adjusted and extended to 12 months, all the criteria 


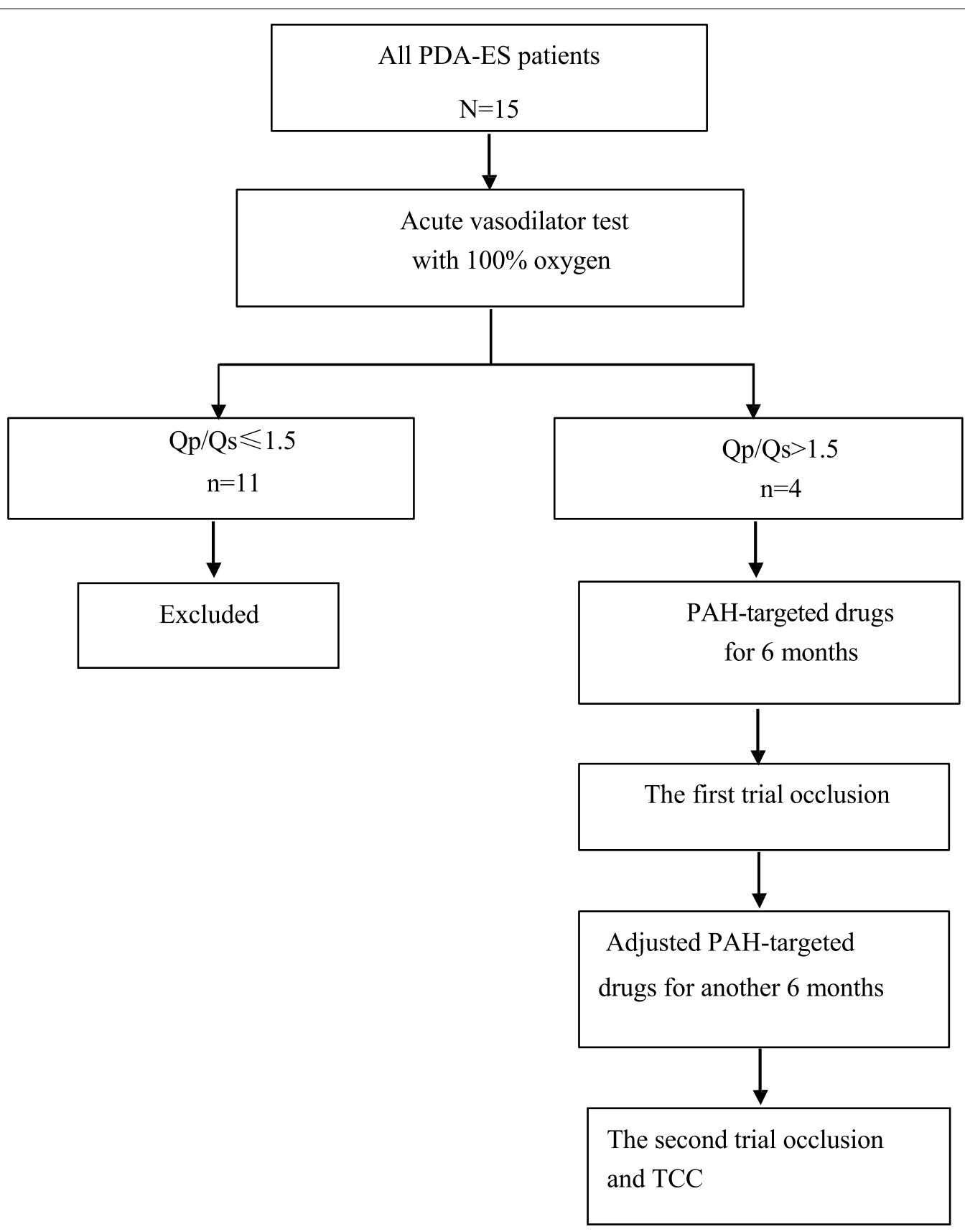

Fig.1 Study flow chart. PDA patent ductus arteriosus, ES Eisenmenger syndrome, Qp/Qs pulmonary-systemic blood flow ratio, PAH pulmonary arterial hypertension, TCC transcatheter closure

Table 1 Baseline demographic characteristics and echocardiography parameters of all patients

\begin{tabular}{llllllll}
\hline Patient (no.) & Sex & Age (years) & WHO FC & 6MWD $(\mathbf{m})$ & LVEF $(\%)$ & RV diameter $(\mathbf{m m})$ & PASP $(\mathbf{m m H g})$ \\
\hline 1 & M & 29 & III & 440 & 53 & $69 * 42$ & 115 \\
2 & F & 19 & II & 400 & 67 & $57 * 29$ & 120 \\
3 & F & 32 & II-II & 170 & 72 & $68 * 40$ & 144 \\
4 & F & 34 & III & 450 & 67 & $75 * 35$ & 104 \\
\hline
\end{tabular}




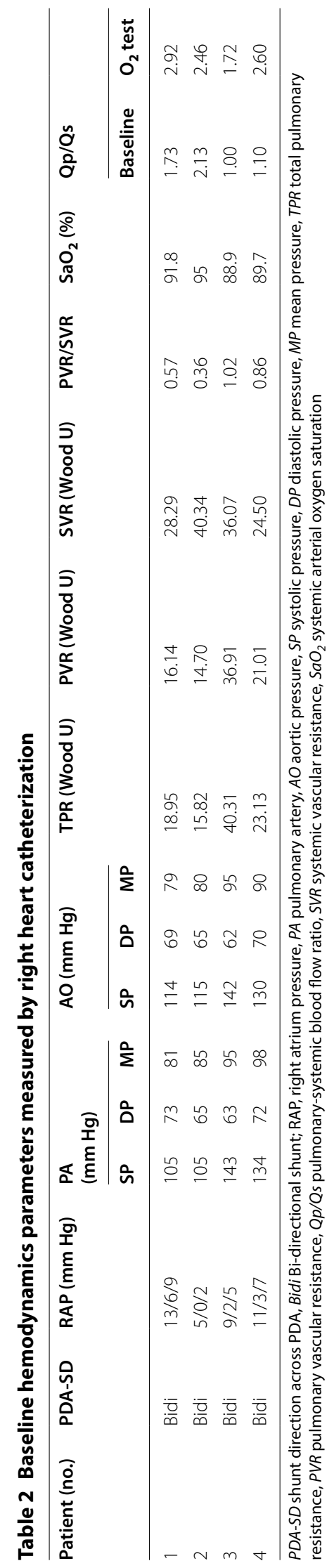


were met and the PDA occluder was released following trial occlusion. There was no residual shunt for all and no complication or adverse event during perioperative period. All patients were discharged with PAHtargeted drugs 1-2 days after TCC. Initial and adjusted PAH-targeted drugs before permanent TCC were shown in Table 3. The PDA diameter, occluder size, changes of PASP, AOP and $\mathrm{SaO}_{2}$ before and after trial occlusion were shown in Table 4.

\section{Follow-up}

At 12-month follow-up, Cases 1 and 2 discontinued targeted therapy because PASP decreased to near normal. Case 2 was treated with ambrisentan again at 60-month as PASP rose to $72 \mathrm{mmHg}$. At 72-month follow-up, the PASP fall to $58 \mathrm{mmHg}$.PASP of Case 3 decreased to $98 \mathrm{mmHg}$ at 12 -month but rose to $140 \mathrm{mmHg}$ at 24-month follow-up after stopping targeted drug without doctor consultant, therefore she was prescribed with bosentan and tadanafil again and the PASP was $111 \mathrm{mmHg}$ at 48 -month follow-up. PASP of Case 4 decreased to $70 \mathrm{mmHg}$ at 12 -month, but the PASP rose again to $87 \mathrm{mmHg}$ and $131 \mathrm{mmHg}$ at 24-month and 36-month, respectively. She was prescribed with macitentan instead of ambrisentan at 29-month follow-up. The changes of PASP measured by echocardiography and

\begin{tabular}{|c|c|c|}
\hline Paitent (no.) & Intial & Adjusted \\
\hline 1 & Vardenafil 5 mg bid & $\begin{array}{l}\text { Vardenafil } 5 \mathrm{mg} \text { bid } \\
\text { Bosentan } 125 \mathrm{mg} \text { bid }\end{array}$ \\
\hline 2 & Tadanafil 20 mg qd & $\begin{array}{l}\text { Tadalafil } 20 \mathrm{mg} \text { qd } \\
\text { Bosentan } 125 \mathrm{mg} \text { bid }\end{array}$ \\
\hline 3 & $\begin{array}{l}\text { Bosentan } 125 \text { mg bid } \\
\text { Tadanafil } 20 \text { mg qd }\end{array}$ & $\begin{array}{l}\text { Bosentan } 125 \mathrm{mg} \text { bid } \\
\text { Tadanafil } 20 \mathrm{mg} \text { qd }\end{array}$ \\
\hline 4 & $\begin{array}{l}\text { Ambrisentan } 5 \mathrm{mg} \text { qd } \\
\text { Tadalafil } 20 \mathrm{mg} \text { qd }\end{array}$ & $\begin{array}{l}\text { Ambrisentan } 5 \text { mg qd } \\
\text { Tadalafil } 20 \text { mg qd }\end{array}$ \\
\hline
\end{tabular}

targeted drugs adjustment of each individual during follow-ups after final TCC were shown in Fig. 2.

All the four patients showed improved 6MWD, WHO FC and $\mathrm{SaO}_{2}$ without enlarged $\mathrm{RV}$ diameter during a mean follow-up of $48 \pm 14.70$ months (ranging from 36 to 72 months). Hemodynamic assessment by RHC showed there was a significant fall in PVR of 3.83Wood $\mathrm{U}$ in case 2. Case 3 and 4 also displayed improved PVR of 12.68Wood U,12.54 Wood U and PVR/SVR of 0.88,0.80, respectively (Table 5). RV diameter, WHO FC, 6MWD and PAH-targeted drugs at the last follow-up were shown in Table 6.

\section{Discussion}

CHDs patients with ES were previously considered to have irreversible pulmonary hypertension. Isolated correction of the cardiac defect in patients with ES has typically been considered as contraindication [11]. Historically, management options for patients with ES have been limited to palliative measures or heart-lung transplantation. The recent introduction of targeted therapies in PAH has led to a renewed insight in the pathophysiology and treatment of ES [11, 12]. Considering ES patients maintain some degree of pulmonary vasoreactivity despite the presence of obstructive pulmonary hypertension [13], ES patients using a diagnostic treatment and repair strategy are amenable to receive surgery or TCC after successful treatment with advanced therapy, but no proof of its efficacy has really been shown in large-scale studies [14-16]. Our study indicated that some selected PDA-ES patients might be amenable to and benefit from TCC over a long follow-up period. Uninterrupted combination of PAH-targeted drugs before and after occlusion play a crucial role especially for the high-risk PDA-ES patients.

It is strongly recommended that PAH-targeted therapies [17-19] for a sufficient period of time to assess the hemodynamic and symptomatic response before closure [13, 14]. Supomo et al. [20] described a atrial septal defect(ASD)-ES female with highly symptomatic

Table 4 Comparisons between pre- and post-occlusion parameters

\begin{tabular}{|c|c|c|c|c|c|c|c|c|c|c|c|c|c|c|c|c|}
\hline \multirow[t]{3}{*}{ Patient (no.) } & \multirow{3}{*}{$\begin{array}{l}\text { PDA } \\
\text { diameter } \\
(\mathrm{mm})\end{array}$} & \multirow{3}{*}{$\begin{array}{l}\text { Occluder } \\
\text { size }(\mathrm{mm})\end{array}$} & \multicolumn{6}{|c|}{$\mathrm{PA}(\mathrm{mmHg})$} & \multicolumn{6}{|c|}{$\mathrm{AO}(\mathrm{mmHg})$} & \multicolumn{2}{|c|}{$\mathrm{SaO}_{2}(\%)$} \\
\hline & & & \multicolumn{3}{|c|}{ Pre- } & \multicolumn{3}{|c|}{ Post- } & \multicolumn{3}{|l|}{ Pre- } & \multicolumn{3}{|c|}{ Post- } & \multirow[t]{2}{*}{ pre- } & \multirow[t]{2}{*}{ post- } \\
\hline & & & SP & DP & MP & SP & $\mathrm{DP}$ & MP & SP & DP & MP & SP & DP & MP & & \\
\hline 1 & 10 & $18-20$ & 105 & 54 & 72 & 56 & 34 & 43 & 113 & 73 & 85 & 124 & 86 & 108 & 96 & 98 \\
\hline 2 & 9 & $16-18$ & 110 & 61 & 84 & 61 & 44 & 53 & 123 & 69 & 94 & 116 & 69 & 91 & 97 & 100 \\
\hline 3 & 9 & $20-22$ & 138 & 58 & 88 & 74 & 27 & 46 & 137 & 67 & 89 & 150 & 70 & 100 & 92 & 100 \\
\hline 4 & 11 & $20-22$ & 145 & 72 & 104 & 72 & 30 & 48 & 144 & 78 & 102 & 153 & 91 & 116 & 97 & 100 \\
\hline
\end{tabular}

$P D A$ patent ductus arteriosus, $P A$ pulmonary artery, $A O$ aorta, $S P$ systolic pressure, $D P$ diastolic pressure, $M P$ mean pressure, $S a O_{2}$ systemic arterial oxygen saturation 


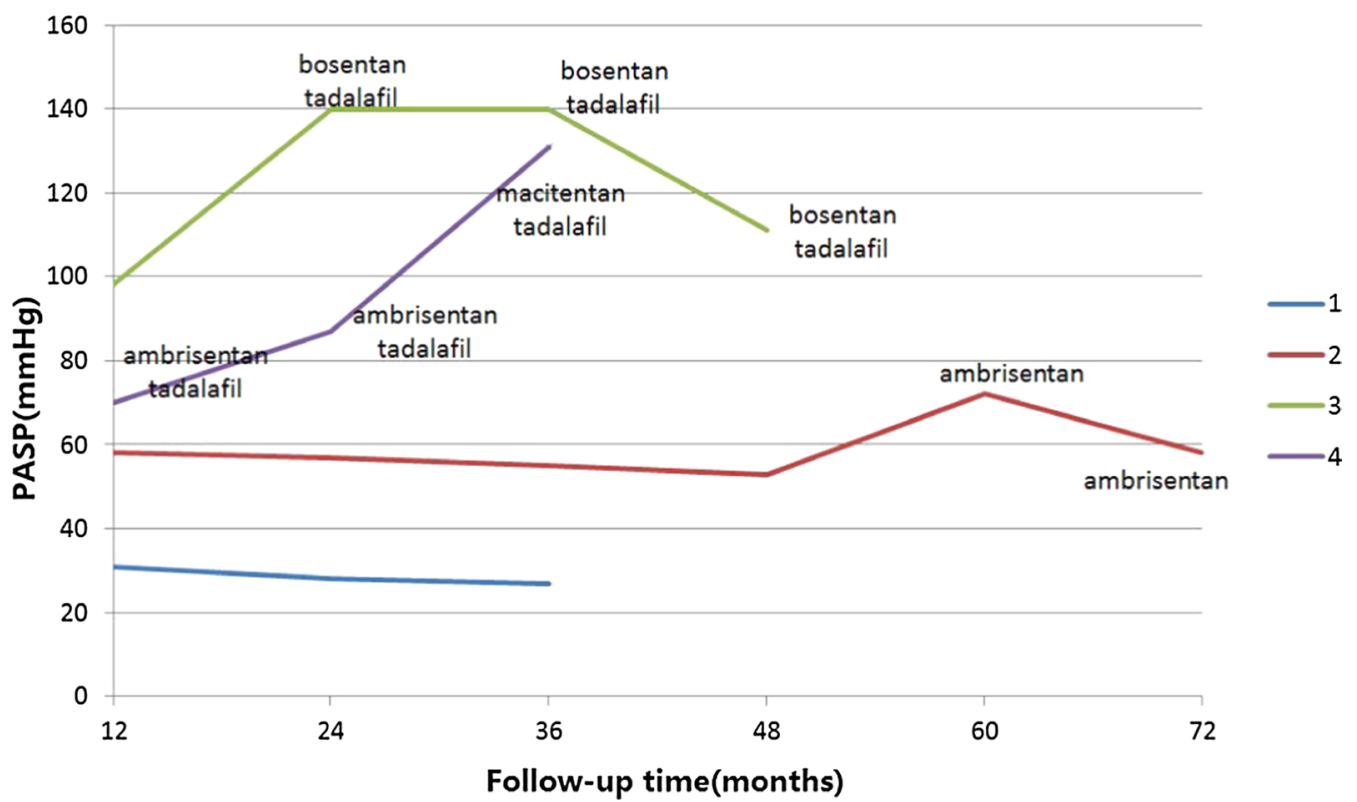

Fig.2 PASP changes on echocardiography and adjustment of targeted drugs at follow-up after final TCC. PASP pulmonary artery systolic pressure, TCC transcatheter closure

Table 5 Hemodynamics parameters measured by right heart catheterization at follow-up

\begin{tabular}{llllllll}
\hline Paitent (no.) & RAP $(\mathbf{m m H g})$ & PASP $(\mathbf{m m H g})$ & $\mathbf{C O}(\mathbf{L} / \mathbf{m i n})$ & $\mathbf{S a O}_{\mathbf{2}}(\%)$ & PVR (Wood U) & SVR (Wood U) & PVR/SVR \\
\hline 2 & $11 / 6 / 9$ & $55 / 18 / 36$ & 6.0 & 98 & 3.83 & 13.33 & 0.29 \\
3 & $15 / 8 / 11$ & $139 / 47 / 82$ & 5.6 & 94.3 & 12.68 & 14.29 & 0.88 \\
4 & $12 / 1 / 6$ & $136 / 54 / 86$ & 5.9 & 92.2 & 12.54 & 15.67 & 0.80 \\
\hline
\end{tabular}

$R A P$ right atrium pressure, $P A S P$ pulmonary artery systolic pressure, $\mathrm{CO}$ cardiac output, $\mathrm{SaO}_{2}$ systemic arterial oxygen saturation, $P V R$ pulmonary vascular resistance, SVR systemic vascular resistance

Table 6 RV diameter, WHO FC,6MWD and PAH-targeted drugs at the last follow-up

\begin{tabular}{lllll}
\hline Paitent (no.) & RV diameter $(\mathbf{m m})$ & WHO FC & 6MWD $(\mathbf{m})$ & PAH-targeted drugs \\
\hline 1 & $50 * 25$ & 1 & 550 & - \\
2 & $55 * 28$ & 1 & 500 & Ambrisentan \\
3 & $65 * 40$ & $\|$ & 440 & Bosentan, tadalafil \\
4 & $59 * 39$ & $\|$ & 490 & Macitentan,tadalafil \\
\hline
\end{tabular}

$R V$ right ventricle, $W H O F C$ WHO functional class, $6 M W D$ six-minute walking distances

PAH(NYHA class III, mean PAP $77 \mathrm{mmHg}$, PVR 4 Wood $\mathrm{U})$ underwent occlusion successfully after oral beraprost for 2 years. After surgery her mean PAP decrease to $38 \mathrm{mmHg}$ with PVR of 2.52 Wood U. Hu et al. [21] reported a ventricular septal defect (VSD)-ES patient with initial PVR of 18.84 Wood U underwent a successful operation after oral bosentan treatment for 12 weeks, as a result of which her PVR decreased to 9.63 Wood U. Four PDA patients in our study were all ES with higher PASP and PVR, indicating that initial combination of PAH-targeted drugs for 1 year at least may provide ES patients a better occlusion opportunity. Especially for ES patients as case 3 and 4 with baseline PVR $>15$ Wood $U$ and Qp/ $\mathrm{Qs}<1.5$, initial dual or triple combination of PAH-target drugs for a longer period of time before occlusion are needed to be taken into account.

Selecting ES patients who can be treated with TCC is an important issue that needs to be addressed. The 
correction indications for PDA patients with severe $\mathrm{PAH}$ are not uniformly defined, including pulmonary artery vasoreactivity and/or the presence of $Q p / Q s$ at least 1.5 to $1.0[2,10]$. A strength of the this study is that all of our patients were classified as ES according to the recent definition [10], the Qp/Qs of the four patients improved significantly and Qp/Qs $>1.5$ following pulmonary vasoreactivity testing were identified with preserved pulmonary vasodilation, which may be deemed candidates for pulmonary vasodilator therapy and TCC.Of note, after PAH-targeted therapy, significant fall of PASP during trial occlusion indicates a likelihood for final TCC $[22,23]$. Yan et al. [24] reported successful occlusion in twenty PDA patients with mean PASP $104 \mathrm{mmHg}$, PVR 9.1 Wood U and Qp/Qs 2.1. A decrease of $>25 \%$ in PASP following trial occlusion was used as the criterion for occlusion. Thanopoulos et al. [25] reported a decrease of $>30 \%$ in PASP as occlusion criterion in seven PDA patients with $\mathrm{Qp} / \mathrm{Qs} \geq 2.0$. Considering our four patients were all ES patients with higher PASP and lower Qp/Qs, our occlusion criteria were stricter. TCC was performed if all the following criteria were met: (1) a drop of $\geq 40 \%$ in PASP; (2) no decrease in AOP; (3) an increase in $\mathrm{SaO}_{2}$. During the follow-up, PASP of case 1,2 decreased further while the other two rose again, therefore the most optimal occlusion criteria were still needed further explored in a larger sample size.

During the long-term follow-up, our four patients displayed improved WHO FC and 6MWD. The PASP of Case 2 deteriorated after interruption of targeted therapy. However, the PASP improved gradually after receiving $\mathrm{PAH}$-targeted therapy again, indicating the $\mathrm{PAH}$ of Case 2 was partially reversible thus targeted therapy could not be discontinued after TCC. Monotherapy would be adoptable needing to be maintained for a long or life-long period. The deteriorated PASPs of Case 3 and 4 indicated the two patients had inadequate $\mathrm{PAH}$-targeted therapy or they might have irreversible pulmonary vascular lesions, therefore more aggressive targeted therapy is needed before and after intervention. Our result suggested uninterrupted dual or triple combination of targeted drugs including oral and intravenous or subcutaneous prostacyclin analogues are also considered for these high-risk PDAES patients after TCC. It is worth noting that PVRs of Cases 3 and 4 decreasing at follow-up in our study suggested improvement of right cardiac function after TCC and pulmonary vasodilator therapy. In general, in spite of initial positive pulmonary vasoreactivity testing and improved hemodynamic status after PAH-targeted therapy, TCC should be performed with caution for such special individuals.

\section{Study limitations}

There are three main limitations in our study. First, the major limitation of the study was the small sample which limited its power. Second, PASP was evaluated by transthoracic echocardiography rather than RHC in most follow-up time. Third, standard pulmonary vasoreactivity testing should include inhaled nitric oxide in addition to $100 \%$ oxygen whereas nitric oxide was not used in our study.

\section{Conclusion}

PDA-ES patients whose PVR $\geq 15$ Wood $U$ at baseline and $\mathrm{Qp} / \mathrm{Qs}>1.5$ on oxygen study might be amenable to and benefit from TCC, after extended period of targeted pulmonary vasodilator therapy up to 1 year. Uninterrupted dual or triple combination of PAHtargeted drugs pre-and post-occlusion play a vital role especially for the high-risk PDA-ES patients.

\begin{abstract}
Abbreviations
PDA: Patent ductus arteriosus; ES: Eisenmenger syndrome; TCC: Transcatheter closure; PASP: Pulmonary artery systolic pressure; CHDs: Congenital heart defects; PVR: Pulmonary vascular resistance; PAH: Pulmonary arterial hypertension; 6MWD: Six-minute walking distance; WHO FC: World Health Organization functional class; RHC: Right heart catheterization; RAP: Right atrial pressure; PAP: Pulmonary artery pressure; PAWP: Pulmonary artery wedge pressure; $\mathrm{CO}$ : Cardiac output; $\mathrm{SvO}_{2}$ : Mixed venous oxygen generation; Qp/Qs: Pulmonary to systemic flow ratio; PVR: Pulmonary vascular resistance; SVR: Systemic vascular resistance; AOP: Aortic pressure; $\mathrm{SaO}_{2}$ : Systemic arterial oxygen saturation; $\mathrm{O}_{2}$ : Oxygen.
\end{abstract}

\section{Acknowledgements}

Not applicable.

\section{Authors' contributions}

All authors contributed to the study conception and design. Material preparation, data collection, and analysis were performed by JX, LW, LG and YLS. The first draft of the manuscript was written by JX, LW. FDC was responsible for the revision of the manuscript for important intellectual content. All authors commented on previous versions of the manuscript and approved the final manuscript.

\section{Funding}

This study received funding from Top-level Clinical Discipline Project of Shanghai Pudong District (PWYgf2018-02). Funding support was used to collect, analyze the data and the travel-related expenses for patient follow-up.

\section{Availability of data and materials}

The datasets used in the case are available from the corresponding author upon reasonable request.

\section{Ethics approval and consent to participate}

This study was approved by theEthical Committee of Shanghai east hospital affiliated to Tongji University.Written informed consent was obtained from all individual participants priorto data collection

\section{Consent for publication}

Written informed consents were obtained from the patients for publication of this study. The copy of the written consents was available for review by the Editor-in-Chief of this journal. 


\section{Competing interests}

The authors declare that they have no competing interests.

Received: 12 June 2020 Accepted: 24 November 2020

Published online: 01 December 2020

\section{References}

1. Adatia I, Kothari SS, Feinstein JA. Pulmonary hypertension associated with congenital heart disease: pulmonary vascular disease: the global perspective. Chest. 2010;137(6 Suppl):52S-61S.

2. Baumgartner $\mathrm{H}$, Bonhoeffer $\mathrm{P}$, De Groot NM, et al. ESC Guidelines for the management of grown-up congenital heart disease (new version 2010). Eur Heart J. 2010;31(23):2915-57.

3. Bhalgat PS, Pinto R, Dalvi BV. Transcatheter closure of large patent ductus arteriosus with severe pulmonary arterial hypertension: short and intermediate term results. Ann Pediatr Cardiol. 2012;5(2):135-40.

4. Varela DL, Teleb M, El-Mallah W. Advanced therapies for the management of adults with pulmonary arterial hypertension due to congenital heart disease: a systematic review. Open Heart. 2018;5(1):e000744.

5. Ereminienè E, Kinderytè M, Miliauskas S, et al. Impact of advanced medical therapy for the outcome of an adult patient with Eisenmenger syndrome. Respir Med Case Rep. 2017:21:16-20.

6. Dimopoulos K, Inuzuka R, Goletto S, et al. Improved survival among patients with eisenmenger syndrome receiving advanced therapy for pulmonary arterial hypertension. Circ Circ. 2010;121(1):20-5.

7. Liu A, Li Z, Li X, et al. Midterm results of diagnostic treatment and repair strategy in older patients presenting with non restrictive ventricular septal defect and severe pulmonary artery hypertension. Chin Med J (Engl). 2014;127(5):839-44

8. Diller GP, Alonso-Gonzalez R, Dimopoulos K, Alvarez-Barredo M, et al. Disease targeting therapies in patients with Eisenmenger syndrome: response to treatment and long-term efficiency. Int J Cardiol. 2013:167(3):840-7.

9. Myers PO, Tissot C, Beghetti M. Assessment of operability of patients with pulmonary arterial hypertension associated with congenital heart disease. Circ J. 2014;78(1):4-11.

10. Daniels CJ, Aboulhosn JA, et al. 2018 AHA/ACC Guideline for the management of adults with congenital heart disease. Circulation. 2018;000:e000-e000.

11. Huang JB, Liang J, Zhou LY. Eisenmenger syndrome: not always inoperable. Respir Care. 2012;57(9):1488-95.

12. Lanigan MJ, Chaney MA, Tissot $C$, et al. Eisenmenger syndrome: close the hole? J Cardiothorac Vasc Anesth. 2014;28(4):1146-53.

13. Budts W, Van Pelt N, Gillyns H, Gewillig M, Van de Werf F, Janssens S. Residual pulmonary vasoreactivity to inhaled nitric oxide in patients with severe obstructive pulmonary hypertension and Eisenmenger syndrome. Heart. 2001;86:553-8.

14. Beghetti M, Galiè N, Bonnet D. Can, "inoperable" congenital heart defects become operable in patients with pulmonary arterial hypertension? Dream or reality? Congenit Heart Dis. 2012;7(1):3-11.

15. Hu Z, Xie B, Zhai X, et al. Midterm results of "treat and repair" for adults with non-restrictive ventricular septal defect and severe pulmonary hypertension. J Thorac Dis. 2015;7(7):1165-73.

16. Yao A. "Treat-and-repair" strategy for atrial septal defect and associated pulmonary arterial hypertension. Circ J. 2016;80(1):69-71.

17. Abd El Rahman MY, Rentzsch A, Scherber P, et al. Effect of bosentan therapy on ventricular and atrial function in adults with Eisenmenger syndrome A prospective, multicenter study using conventional and Speckle tracking echocardiography. Clin Res Cardiol. 2014;103(9):701-10.

18. Mukhopadhyay S, Sharma M, Ramakrishnan S, et al. Phosphodiesterase-5 inhibitor in eisenmenger syndrome: a preliminary observational study. Circulation. 2006;114(17):1807-10.

19. D'Alto M, Diller GP. Pulmonary hypertension in adults with congenital heart disease and Eisenmenger syndrome: current advanced management strategies. Heart. 2014;100(17):1322-8.

20. Supomo S, Hartopo AB, Anggrahini DW, et al. Large atrial septal defect closure in a patient with severe pulmonary arterial hypertension. Korean J Thorac Cardiovasc Surg. 2017;50(5):378-81.

21. Hu L, Tan L-H, Ye J. Repair of ventricular septal defect with Eisenmenger syndrome after Bosentan treatment. J Card Surg. 2014;29(3):401-2.

22. Duan-zhen Zhang MD, Xian-yang Zhu MD, Bei Lv MD, et al. Trial occlusion to assess the risk of persistent pulmonary arterial hypertension after closure of a large patent ductus arteriosus in adolescents and adults with elevated pulmonary artery pressure. Circ Cardiovasc Interv. 2014;7:473-81.

23. Sadiq M, Rehman AU, Hyder N, et al. Intermediate- and long-term followup of device closure of patent arterial duct with severe pulmonary hypertension: factors predicting outcome. Cardiol Young. 2017;27(1):26-36.

24. Yan C, Zhao S, Jiang S, et al. Transcatheter closure of patent ductus arteriosus with severe pulmonary arterial hypertension in adults. Heart. 2007:93(4):514-8.

25. Thanopoulos BD, Tsaousis GS, Djukic M, et al. Transcatheter closure of high pulmonary artery pressure patent ductus arteriosus with Amplatzer muscular ventricular septal occluder. Heart. 2002;87(3):260-3.

\section{Publisher's Note}

Springer Nature remains neutral with regard to jurisdictional claims in published maps and institutional affiliations.
Ready to submit your research? Choose BMC and benefit from:

- fast, convenient online submission

- thorough peer review by experienced researchers in your field

- rapid publication on acceptance

- support for research data, including large and complex data types

- gold Open Access which fosters wider collaboration and increased citations

- maximum visibility for your research: over 100M website views per year

At BMC, research is always in progress.

Learn more biomedcentral.com/submissions 